10.2478/aucft-2021-0002

\title{
A COMPARATIVE ANALYSIS OF DIFFERENT VARIETAL OF FRESH AND DRIED FIGS BY IN VITRO BIOACCESSIBILITY OF PHENOLIC COMPOUNDS AND ANTIOXIDANT ACTIVITIES
}

\author{
- Research paper -
}

\begin{abstract}
Farida KEHAL*, Loucif CHEMACHE ${ }^{1 * *}$, Makhlouf CHAALAL***, Meriem BENBRAHAM**, Esra CAPANOGLU****, Malika BARKAT*
\end{abstract}

\author{
*Laboratoire BIOQUAL, Institut de la Nutrition, de l'Alimentation et des Technologies Agro- \\ Alimentaires (INATAA), Université Frères Mentouri Constantine 1, Route de Ain-El-Bey 25000, \\ Constantine, Algérie. \\ **Laboratoire LNTA, Institut de la Nutrition, de l'Alimentation et des Technologies Agro- \\ Alimentaires (INATAA), Université Frères Mentouri Constantine 1, Route de Ain-El-Bey 25000, \\ Constantine, Algérie. \\ ***Laboratoire de Biochimie Appliquée, Faculté des Sciences de la Nature et de la Vie, Université \\ de Bejaia, 06000 Bejaia, Algérie. \\ ****Department of Food Engineering, Faculty of Chemical and Metallurgical Engineering, \\ Istanbul Technical University, 34469 Maslak, Istanbul, Turkey.
}

\begin{abstract}
Varietal and sun-drying effects on phenolic compounds and their antioxidant activity were investigated during the in vitro gastrointestinal digestion of fresh and dried figs. The total phenolic compounds (phenolic, flavonoids, and proanthocyanidin) and their antioxidant activity (ferric reducing power; free radical scavenging activity DPPH, and phosphomolybdenum test) were evaluated before and after digestion. The total phenolic compounds and the antioxidant capacities of fresh and dried figs obtained before digestion were significantly $(p<0.05)$ higher than those obtained after digestion. A significant decrease $(p<0.05)$ of phenolic compounds and their antioxidant activity was observed during different digestion phases (oral phase $>$ gastric phase $>$ intestinal phase). A positive correlation was found between the total phenolic compounds and the antioxidant activity tested for both fresh and dried figs. Furthermore, the results showed that the digestion has no effect on the total phenolic compounds; however, a negative influence of the $\mathrm{pH}$ and the enzymes was observed on these compounds and their antioxidant activity. During in vitro gastrointestinal digestion, the varietal and the sun-drying has no significant effect on the phenolic compounds and their antioxidant activity. Likewise, the fresh or dry variety kept a high content before and after the digestion.
\end{abstract}

Keywords: In vitro gastrointestinal digestion; figs; phenolic compounds; antioxidant activity; varietal effect; sun-drying effect.

\section{INTRODUCTION}

Figs are the fruit of fig tree (Ficus carica L.). This fruit was originated in the Middle East and is naturalized in several regions and especially those around the Mediterranean area. According to the FAO (2018), Algeria is the third producer of dried figs with an annual production of 131,798 tons, which represents $12.55 \%$ of world production.

Figs are an excellent source of phenolic compounds and have a strong antioxidant activity, which can

Received: 24.01.2021

Accepted in revised form: 20.05.2021 prevent several diseases (Chawla et al., 2012; Debib et al., 2014; Jolayemi et al., 2020). Recently, more attention has been paid to phenolic compounds and their bioaccessibility, which is defined as the amount of a constituent released from a food matrix into the lumen of the gastrointestinal tract, which could potentially be available for absorption in the body through the intestinal barrier. Polyphenols are ingested as complex mixtures immersed in a food matrix. Only the polyphenols released by the action of digestive enzymes in the small intestines and bacterial microflora in the large intestine are

${ }^{1}$ Corresponding author. E-Mail address: chemache_loucif@yahoo.fr,$\underline{\text { chemache.loucif@umc.edu.dz }}$ 
bioaccessible in the intestine and, therefore, potentially bioavailable (Saura-Calixto et al., 2007).

Human studies have taken a long time and they are costly and limited by ethical considerations. In vitro models, the study of the effects of digestion have been developed and used to predict the release of polyphenols from the food matrix and assess changes in their profiles before absorption (Kamiloglu et al., 2015). These in vitro methods have been developed as an alternative approach to in vivo studies and are considered as simple tools. They have the advantage of being faster, less expensive, less manpower and with no ethical restrictions (Minekus et al., 2014).

Many studies were evaluated the effect of in vitro digestion on dietary polyphenols in several fruits such as apples (Bouayed et al., 2011), strawberries (Granese et al., 2014), pomegranate (Gullon et al., 2015), grapes (Zoubiri et al., 2019), carob (Ydjedd

\section{MATERIALS AND METHODS}

\section{Plant Material}

Three different varieties (Aberkane, Azandjar, and Taamriwt) of fig fruits were harvested and dried by fig grower's cooperative from Beni Maouche area, Bejaia, which is located in the Northeast of Algeria. The varieties were different in their color; the first two had a dark color and the third had a light color. Drying method was conducted under the sun for 9 days in August. The figs were spread on reed trays in a single layer in an airy and sunny place. They were turned from time to time to ensure a homogeneous drying. At the end of each day, the reed trays were placed inside to prevent absorption of moisture during night. The samples were lyophilized (Christ, Alpha 1-4 LD plus, Germany), ground with a crusher (IKA A 11 B, Germany), and passed through a $500 \mu \mathrm{m}$ sieve. The sample powders were kept in the freezer $\left(-18{ }^{\circ} \mathrm{C}\right)$ until further analysis.

\section{In vitro gastrointestinal digestion (IVGID)}

In vitro gastrointestinal digestion of the whole powders of fresh and dried figs was carried out according to the method described by Ydjedd et al. (2017). In vitro gastrointestinal digestion of samples consists of a three-step procedure, which simulates in the mouth (oral phase), in the stomach (gastric digestion), and in the small intestines (duodenal digestion) using different digestive enzymes such as $\alpha$-amylase, pepsin, and pancreatin, respectively. The whole figs powders before digestion phase was taken as a control. et al., 2017) and prickly pears (Chaalal et al., 2018). However, few studies have put interest on the effect of in vitro gastrointestinal digestion on phenolic compounds of fresh and dried figs. In addition, the effects of variety and sun-drying figs on the in vitro gastrointestinal digestion of their phenolic compounds have been insufficiently investigated. Varietal diversity and sun-drying of figs can have a significant effect on the contents of phenolic compounds and their antioxidant activity during gastrointestinal digestion (Kamiloglu and Capanoglu, 2013).

In this work, we investigate the varietal and sundrying effect on the bioaccessibility of phenolic compounds (total phenolics, total flavonoids, and proanthocyanidins) and their antioxidant activity during the in vitro gastrointestinal digestion of three Algerian fresh and dried figs varieties (Aberkane, Azandjar, and Taamriwt).

\section{Phenolic extraction procedure}

The extraction was carried out by mixing $1 \mathrm{~g}$ of fig powder with $20 \mathrm{~mL}$ of distilled water on a shaker plate at room temperature for $60 \mathrm{~min}$. The mixture was centrifuged at $4000 \mathrm{rpm}$ for $15 \mathrm{~min}$ and filtered using filter paper. The extracts were stored at $4{ }^{\circ} \mathrm{C}$ until further analysis.

\section{Determination of phenolic compounds Total phenolics content (TPC)}

The total phenolic content was quantified according to the Folin-Ciocalteu method described by Spanos and Wrolstad (1990). A volume of $1 \mathrm{~mL}$ of the extract, before and after each digestion phases, was mixed with $5 \mathrm{~mL}$ of folin-Ciocalteu reagent $(0.2 \mathrm{~N})$. After $3 \mathrm{~min}$ of incubation at room temperature, 4 $\mathrm{mL}$ sodium carbonate $\left(\mathrm{Na}_{2} \mathrm{CO}_{3}, 2 \%\right)$ were added. After $2 \mathrm{~h}$ of incubation in the dark at room temperature, the absorbance was measured at 750 $\mathrm{nm}$. The results were expressed as milligrams of gallic acid equivalent per 100 grams of dry matter (mg GAE/100 g DM).

\section{Total flavonoids content (TFC)}

The total flavonoids content was determined by the aluminum trichloride method $\left(\mathrm{AlCl}_{3}\right)$ which was described previously by Dewanto et al. (2002). A volume of $0.25 \mathrm{~mL}$ of extract was mixed with 1.25 $\mathrm{mL}$ of distilled water and $75 \mu \mathrm{l}$ of sodium nitrite solution $\left(\mathrm{NaNO}_{2}, 5 \%\right)$. After 6 min of incubation at room temperature, $150 \mu \mathrm{l}$ of aluminum trichloride $\left(\mathrm{AlCl}_{3} 6 \mathrm{H}_{2} \mathrm{O}, 10 \%\right)$ were added. After $5 \mathrm{~min}, 0.5 \mathrm{~mL}$ of $\mathrm{NaOH}(1 \mathrm{M})$ was added. The volume was adjusted to $2.5 \mathrm{~mL}$ with distilled water. The absorbance was measured directly at $510 \mathrm{~nm}$. The 
TFC was calculated by referring to a standard curve obtained using quercetin as a standard. The results were expressed as milligrams quercetin equivalent per 100 grams of dry matter (mg QE/100 g DM).

\section{Total proanthocyanidins content (TPrC)}

The proanthocyanidins content was determined according to the butanol- $\mathrm{HCl}$ method described previously by Škerget et al. (2005). A volume of 0.5 $\mathrm{mL}$ of extract was added to $2 \mathrm{~mL}$ of the butanol- $\mathrm{HCl}$ reagent $(77 \mathrm{mg} \mathrm{FeSO}$ dissolved in $500 \mathrm{~mL} \mathrm{HCl}-$ butanol (2:3)). The mixture was incubated at $95^{\circ} \mathrm{C}$ for $15 \mathrm{~min}$. In the acidic medium and under the effect of heat, the proanthocyanidins were dissociated and gave a specific coloration. The absorbance was measured at $530 \mathrm{~nm}$. The results were determined according to Beer-lambert's law (Eq. 1) using cyanidine as a standard (MW $=287.24$ $\mathrm{g} / \mathrm{mol}, \quad \varepsilon=34700 \mathrm{l} / \mathrm{mol} / \mathrm{cm})$. The TPrC was expressed as milligrams cyanidine equivalent per 100 grams of dry matter (mg CE/100 g DM).

$$
A=\mathcal{E} . C . L \quad \text { Eq. } 1
$$

\section{Determination of antioxidant activities Ferric reducing power (FRP)}

The ferric reducing power was determined according to the method described previously by Oyaizu (1986). A volume of $0.5 \mathrm{~mL}$ of extract was added to $0.5 \mathrm{~mL}$ of phosphate buffer $(0.2 \mathrm{M}, \mathrm{pH} 6.6)$ and $0.5 \mathrm{~mL}$ of potassium ferricyanide $(1 \%)$. After incubation at $50{ }^{\circ} \mathrm{C}$ for $20 \mathrm{~min}, 0.5 \mathrm{~mL}$ of trichloroacetic acid (10\%) was added to the mixture. After centrifugation at $1700 \mathrm{~g}$ for $15 \mathrm{~min}$, an aliquot of $1 \mathrm{~mL}$ of the supernatant was mixed with $1 \mathrm{~mL}$ of distilled water and $0.2 \mathrm{~mL}$ of ferric chloride $(0.1 \%)$. After incubation in the darkness for $10 \mathrm{~min}$, the absorbance was measured at $700 \mathrm{~nm}$. The results were expressed as milligrams ascorbic acid equivalent per 100 grams of dry matter $(\mathrm{mg}$ $\mathrm{AAE} / 100 \mathrm{~g} \mathrm{DM})$.

\section{RESULTS}

\section{Phenolic compounds \\ Total phenolic content}

The TPC of three fresh and dried figs varieties before and during IVGID are presented in Figure 1. Before digestion, the fresh figs revealed high levels of TPC with values of 456.88, 381.33 and 197.24 mg GAE/ $100 \mathrm{~g}$ DM for the Aberkane, Taamriwt, and Azandjar varieties, respectively. A significant difference $(p<0.05)$ was observed in the TPC between the three fresh figs varieties before digestion and after oral and gastric phases. Likewise, in the intestinal phase, only the TPC of

\section{Free radical scavenging activity (FRSA)}

Free radical scavenging activity DPPH was determined according to the method described previously by Kumaran and Joel karunakaran (2006). A volume of $100 \mu \mathrm{l}$ of extract was added to $2000 \mu \mathrm{l}$ of the 2-diphenyl-1-picrylhydrazyl solution (DPPH) $(0.1 \mathrm{mM})$. The mixture was incubated for $30 \mathrm{~min}$ in the darkness and the absorbance was measured at $517 \mathrm{~nm}$. The results were expressed as milligrams ascorbic acid equivalent per 100 grams of dry matter (mg AAE/100 g DM).

\section{Phosphomolybdenum test (PhM)}

The antioxidant activity was also evaluated by the phosphomolybdate method described previously by Prieto et al. (1999). A volume of $2 \mathrm{~mL}$ of the phosphomolybdate reagent $(0.6 \mathrm{~mol} / \mathrm{l}$ of sulfuric acid, $28 \mathrm{mmol} / \mathrm{l}$ of sodium phosphate and $4 \mathrm{mmol} / \mathrm{l}$ of ammonium molybdate) was added to $200 \mu \mathrm{l}$ of extract. After incubation for $90 \mathrm{~min}$ at $95{ }^{\circ} \mathrm{C}$, the absorbance was measured at $695 \mathrm{~nm}$. The results were expressed as milligrams gallic acid equivalent per $100 \mathrm{~g}$ of dry matter (mg GAE/100 g DM).

\section{Statistical analysis}

All analyses were carried out in triplicate and the results were reported as mean \pm standard deviation. Statistica 5.5 software (StatSoft ${ }^{\circledR}$ Inc. USA) was used to perform the analysis of ANOVA followed by the post-hoc Tukey HSD test to analyze the significance of the differences between homogeneous groups at a significance level of 0.05 . Principal Components Analysis (PCA) was carried out using the XLSTAT software (Version 2009.1.01. Addinsoft ${ }^{\circledR}$ ). This factor analysis also allows the conduction of Person (n) correlation tests to visualize possible correlations between phenolic compounds and their antioxidant activities.

Aberkane variety was significantly different $(p<$ 0.05 ) from the two other varieties studied (Figure 1a).

Before digestion and after the oral phase, a significant difference was observed between the TPC of three dried varieties studied. Indeed, the Azandjar variety presents a highest TPC with values of 270.48 and $263.43 \mathrm{mg} \mathrm{GAE} / 100 \mathrm{~g} \mathrm{DM}$ before digestion and after the oral phase, respectively, followed by the Aberkane and Taamriwt varieties. After the gastric and intestinal phases, no significant difference $(p>0.05)$ was observed between the both varieties with dark color (Aberkane and azandjar), however, only Taamriwt variety was significantly 
different $(p<0.05)$ from the other varieties which presents à lowest TPC after the last two digestion phases (Figure 1b).

Concerning the fresh figs, a significant difference ( $p$ $<0.05)$ was recorded between the different digestion phases (Figure 1c). For the Aberkane variety, a significant decrease $(p<0.05)$ in TPC was observed between the different digestion phases. However, a lowest TPC was obtained in the intestinal phase with a decrease rate of $38.36 \%$. For Azandjar variety, an increase about $30.10 \%$ was recorded after the oral phase. Then, a decrease was noted after gastric and intestinal phases with rates reaching 20.65 and $25.43 \%$ respectively. Regarding TPC of Taamriwt variety, a significant decrease $(p$ $<0.05)$ was observed after oral, gastric, and intestinal phases with rates reached of $42.56 \%$, $63.74 \%$, and $61.49 \%$, respectively.
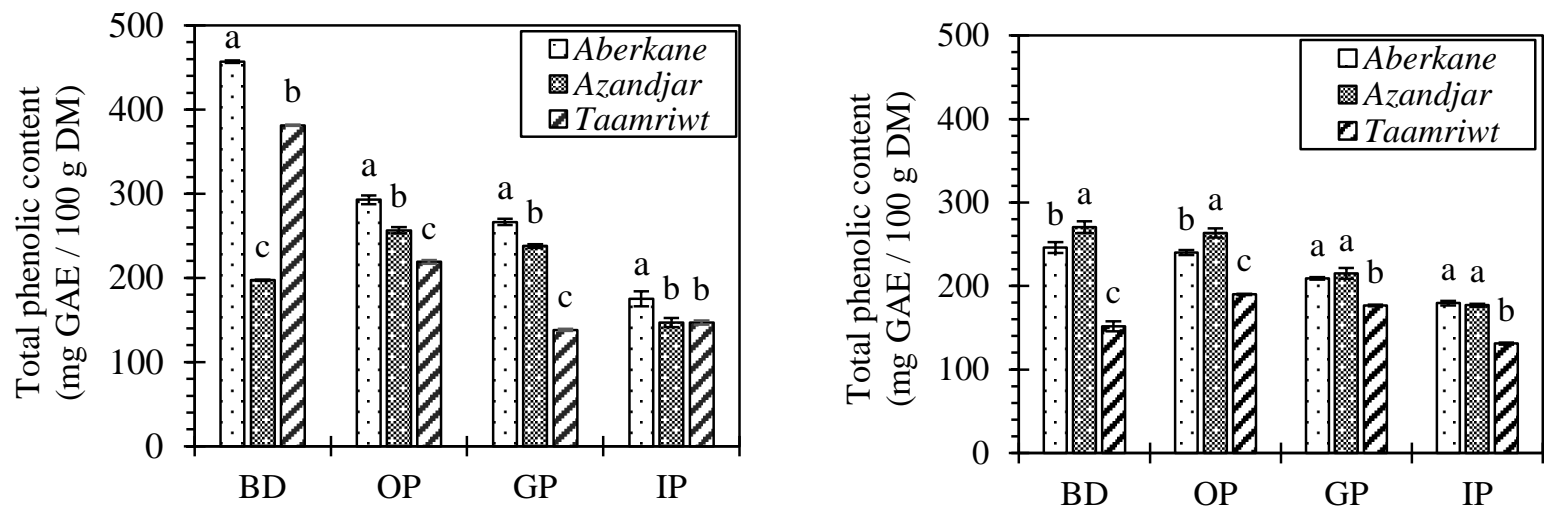

\section{Fresh figs}

(a)

\section{Dried figs}

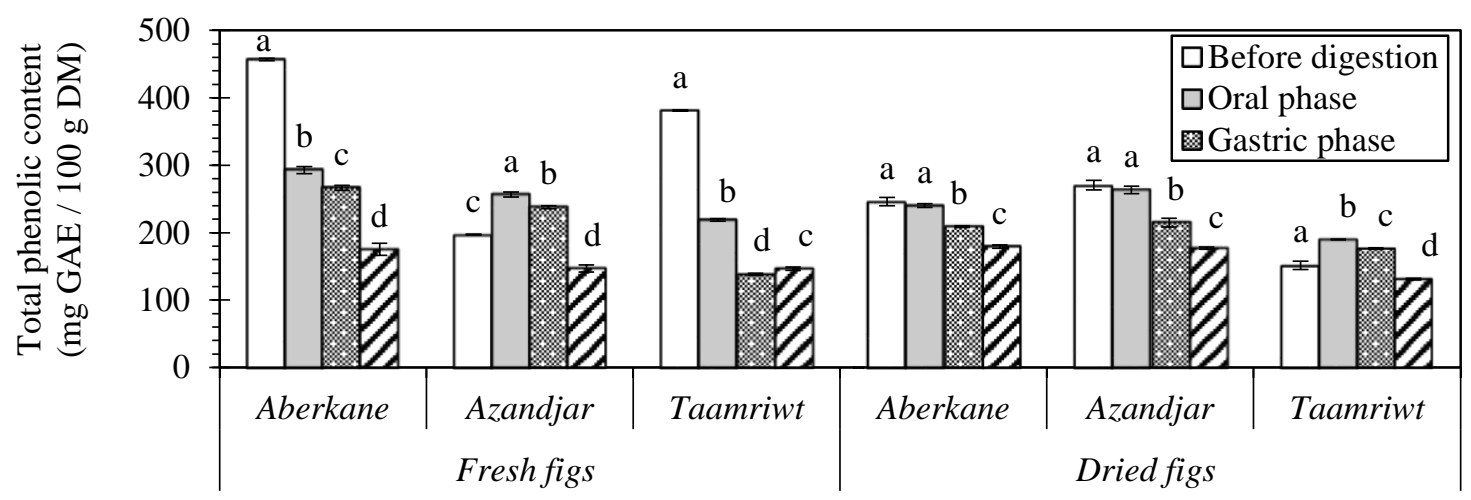

(b)

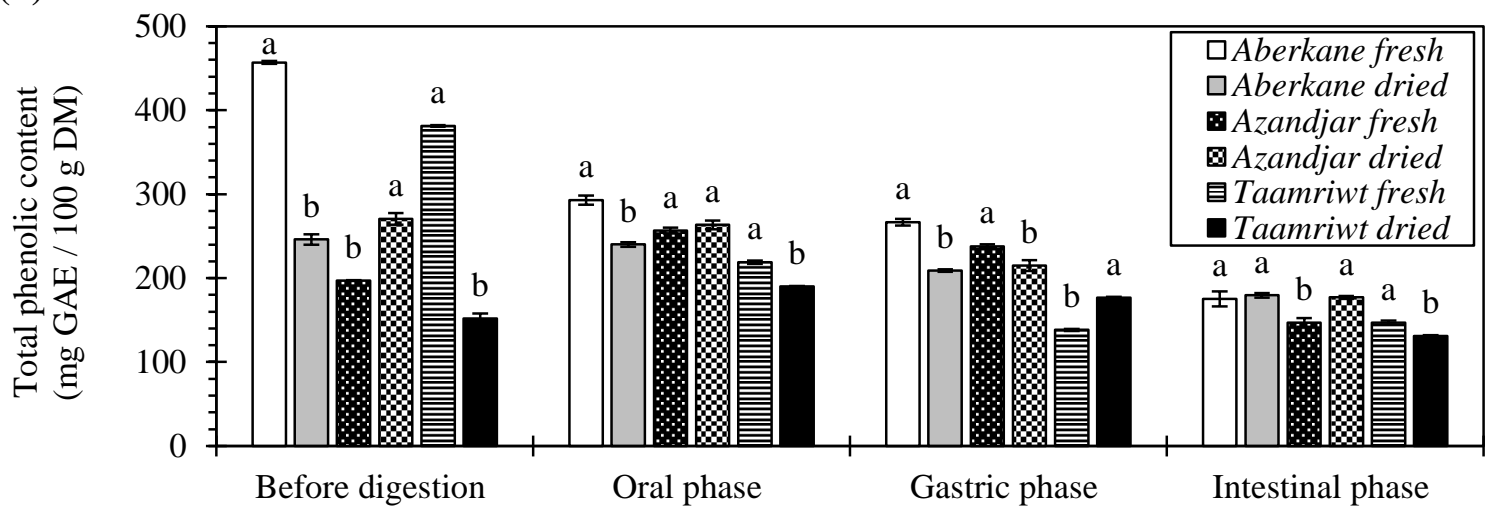

(c)

Figure 1. Varietal (a), in vitro gastrointestinal digestion (b), and sun-drying (c) effects on total phenolic content of fresh and dried figs during the in vitro gastrointestinal digestion phases (BD: before digestion, OP: oral phase, GP: gastric phase, IP: intestinal phase) 
The dried figs showed clearly that the TPC changed differently during the IVGID. For Aberkane variety, no significant difference was revealed $(p>0.05)$ between before digestion and oral phase. Nevertheless, a significant decrease in TPC $(p<$ $0.05)$ was recorded after the gastric and intestinal phases with decrease rates of 15.04 and $27.06 \%$ respectively. In addition, no significant difference ( $p>0.05)$ in TPC of the Azandjar variety was noted between before digestion and after oral phase. Lilkewise, a significant decrease $(p<0.05)$ was showed for the gastric and intestinal phases with rates of 20.57 and $34.52 \%$ respectively. For Taamriwt variety, a significant increase $(p<0.05)$ in the TPC was noted. This increase displays rates of 25.25 and $16.37 \%$ for the oral phase and the gastric phase respectively. Then, the results showed a decrease after the intestinal phase that reached $13.62 \%$ compared to the phase before digestion.

Figure 1c showed the effect of sun-drying on the TPC during the different phases of IVGID. It is clear that TPC of fresh figs was significantly different $(p$ $<0.05$ ) from those recorded with dried figs. For the Aberkane and Taamriwt varieties, fresh figs showed higher TPC compared to Azandjar variety, which was increased under the sun-drying effect

After the oral phase, it appears that the TPC of Aberkane and Taamriwt varieties was higher in fresh figs. However, it should be noted that no significant difference was recorded $(p>0.05)$ between the TPC of fresh and dried figs of the Azandjar variety. After the gastric phase, the total phenolic contents of Aberkane variety was higher in the fresh figs than in the dry ones. Furthermore, the TPC of fresh figs of Taamriwt variety decrease significantly $(p<0.05)$ compared to those of dry figs for the same variety.

\section{Total flavonoids content}

The results of the varietal and the in vitro gastrointestinal digestion effects of the TFC of fresh and dried figs are shown in Figure 2a and Figure $2 b$ respectively. A significant difference $(p<0.05)$ was observed between the TFC of three varieties studied before digestion and oral phase. The Aberkane variety showed a highest levels of TFC whether for fresh or dried figs followed by Azandjar and Taamriwt varieties, respectively. In the gastric phase, an increases in the TFC was noted for the Abekane and Azandjar varieties, and, the Taamriwt variety remains significantly different $(p<0.05)$ from the other varieties. Likewise, a low TFC was obtained for three varieties studied after the intestinal phase without significant difference $(p>$ $0.05)$.
As shown in the Figure $2 b$, the TFC of fresh varieties before digestion were $39.77,28.82$, and $24.71 \mathrm{mg}$ QE/100 g DM for Aberkane, Taamriwt, and Azandjar, respectively. However, the TFC of dried varieties showed lower values, which were 31.39, 23.70 and $17.51 \mathrm{mg}$ QE / $100 \mathrm{~g} \mathrm{DM}$ for Aberkane, Azandjar and Taamriwt, respectively. The statistical analysis showed a significant difference $(p<0.05)$ before digestion between the three varieties of fresh figs and between those of dried ones.

The TFC decreased significantly $(p<0.05)$ during the in vitro gastrointestinal digestion, except Taamriwt variety. Indeed, the TFC were decreased from 53.85 to $18.16 \%$ and from 97.76 to $37.34 \%$ for fresh figs of Aberkane and Azandjar varieties respectively, and from 57.69 to $27.05 \%$ and from 98.69 to $32.46 \%$ for dried figs of Aberkane and Azandjar varieties respectively.

The results of the sun-drying effect on the TFC are shown in Figure 2c. It appears that before digestion, the sun-drying of figs has an effect on the TFC of Abekane and Thaamriwt varieties. However, the TFC of Azandjar variety seems not be affected by the sun-drying. Indeed, no significant difference $(p$ $>0.05$ ) was observed between the TFC levels before and after sun-drying. In addition, no significant difference $(p>0.05)$ was revealed before and after sun-drying for the three varieties studied after the oral phase. Likewise, a significant difference ( $p>$ 0.05 ) was observed between the TFC of fresh and dry varieties after the gastric phase. After the intestinal phase, the results showed no significant difference $(p>0.05)$ between the fresh and dry varieties.

\section{Proanthocyanidin content}

The results of the varietal effect on the TPrC of three fresh and dried are shown in Figure 3a. The obtained results showed a significantly different $(p<0.05)$ between TPrC before digestion, oral and gastric phases. However, no significant difference was observed after the intestinal phase between the fresh figs varieties. For the dried figs, both dark colored varieties seem to have comparable $\mathrm{TPrC}$ with values of 9.08 and $9.85 \mathrm{mg} \mathrm{CE} / 100 \mathrm{~g}$ DM for Aberkane and Azandjar varieties, respectively. Likewise, Taamriwt variety showed a lowest TPrC $(6.91 \mathrm{mg}$ $\mathrm{CE} / 100 \mathrm{~g})$ without significant difference $(p>0.05)$ with the Azandjar variety.

The results of the IVGID digestion effect on TPrC are reported in Figure 3b. Before digestion, the values of the TPrC of the three fresh varieties were 46.61, 40.04 and $33 \mathrm{mg} \mathrm{CE} / 100 \mathrm{~g} \mathrm{DM}$ for the Azandjar, Aberkane and Taamriwt varieties, respectively. However, the contents of fresh figs 
were 34.77, 28.74 and $25.86 \mathrm{mg} \mathrm{CE} / 100 \mathrm{~g} \mathrm{DM}$ for Aberkane, Taamriwt and Azandjar varieties, respectively.

In the oral phase, the increase of TPrC of Taamriwt fresh variety was $24.81 \%$, however, the increase rates of the dried varieties were $12 \%, 35 \%$, and $26.58 \%$ for Aberkane, Azandjar, and Taamriwt varieties, respectively. These values seems higher compared to those obtained before digestion. For the dried varieties, the TPrC was increased significantly $(p<0.05)$ after the oral phase for the

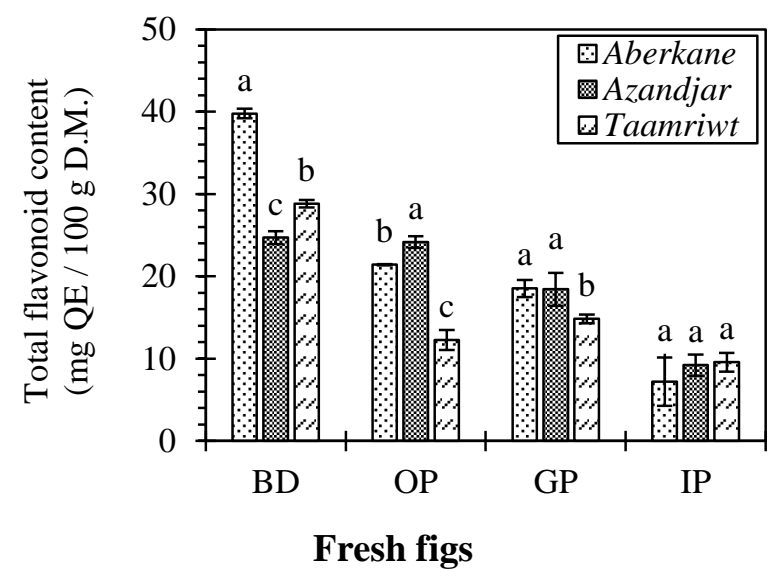

three varieties and it was significant decreased $(p<$ 0.05 ) after the gastric phase.

The sun-drying effect on the evolution of TPrC during IVGID are shown in Figure 3c. Before digestion, it appears that sun-drying leads to a significant reduction $(p<0.05)$ in the TPrC. The fresh varieties contain higher TPrC than the dry ones. After the oral phase, no sun-drying affect was observed on the TPrC of Aberkane and Azandjar varieties.

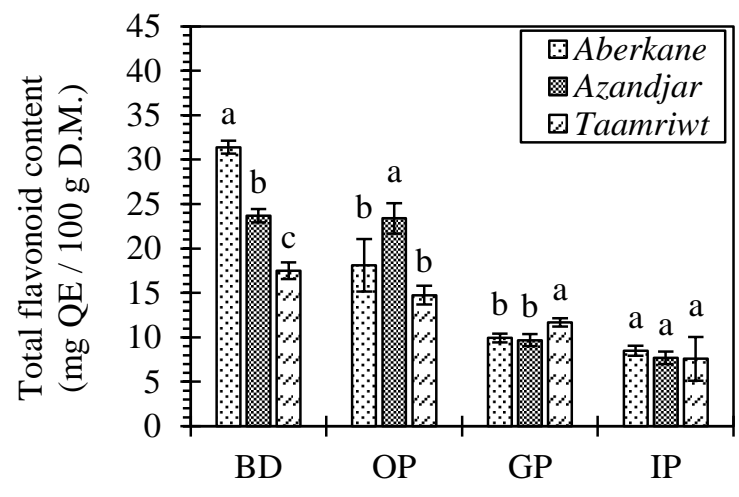

Dried figs

(a)

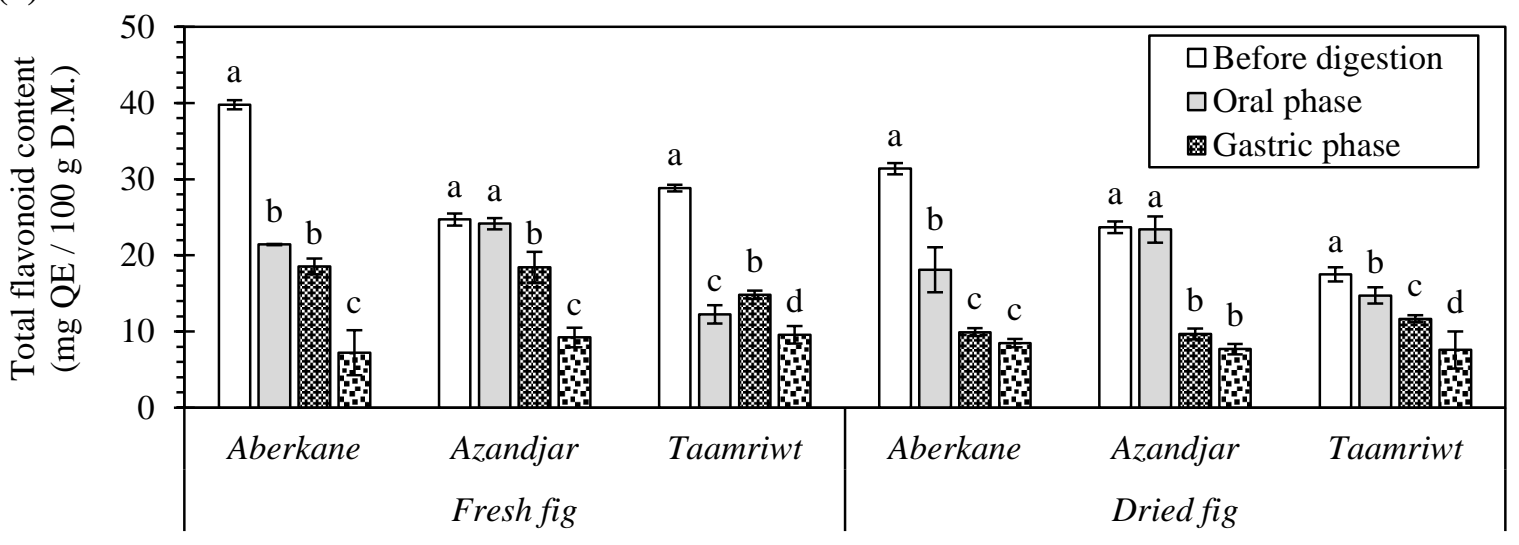

(b)

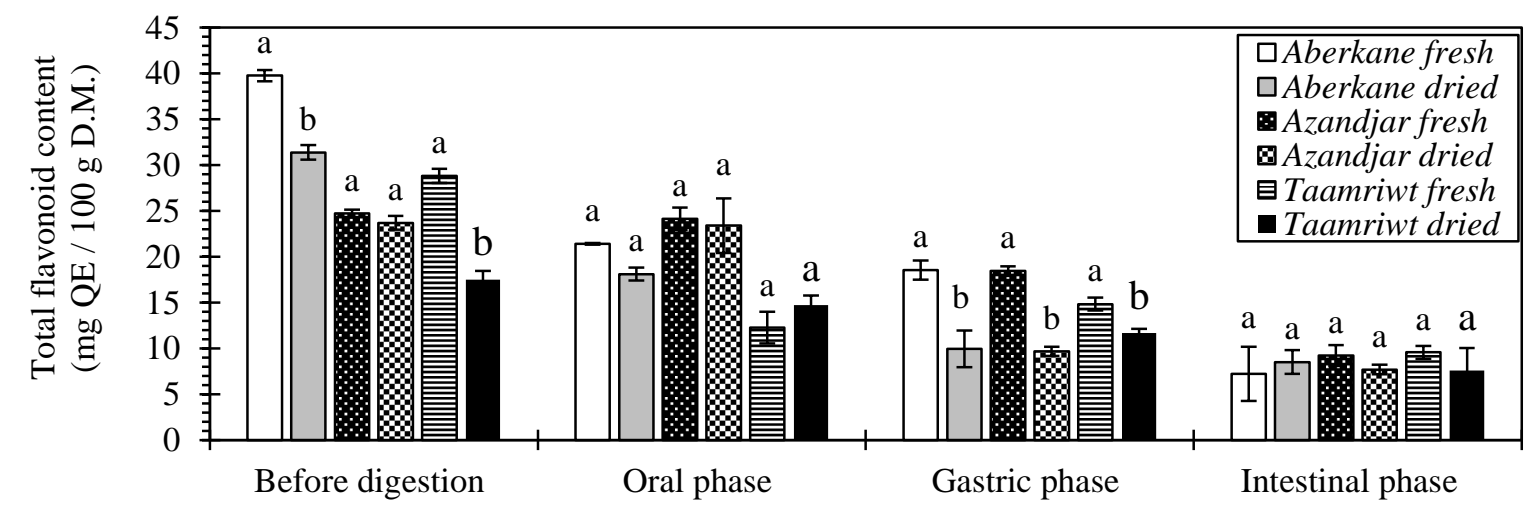

(c)

Figure 2. Varietal (a), in vitro gastrointestinal digestion (b), and sun-drying (c) effects on total flavonoid content of fresh and dried figs during the in vitro gastrointestinal digestion phases (BD: before digestion, OP: oral phase, GP: gastric phase, IP: intestinal phase) 


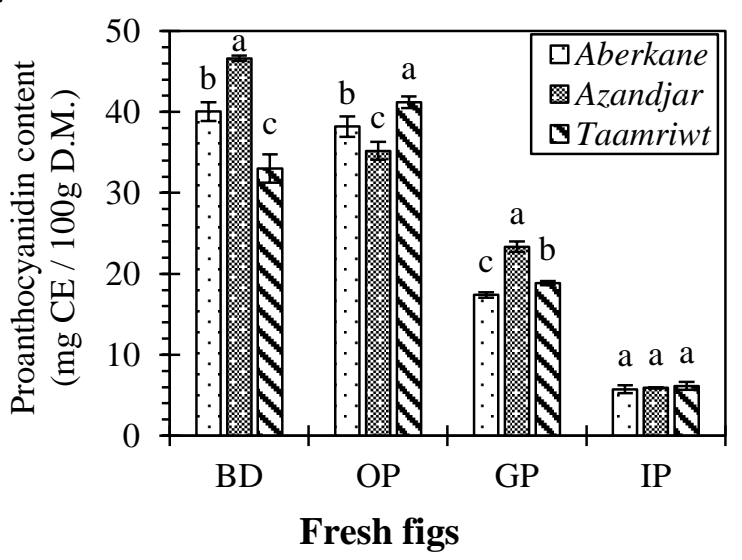

Fresh figs

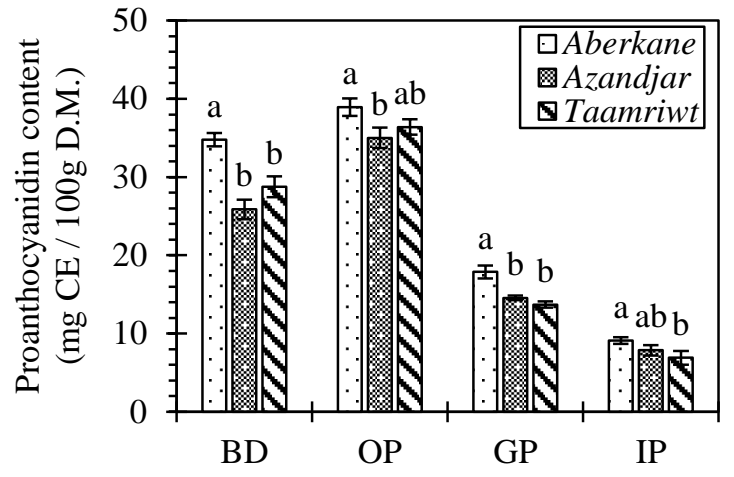

Dried figs

(a)

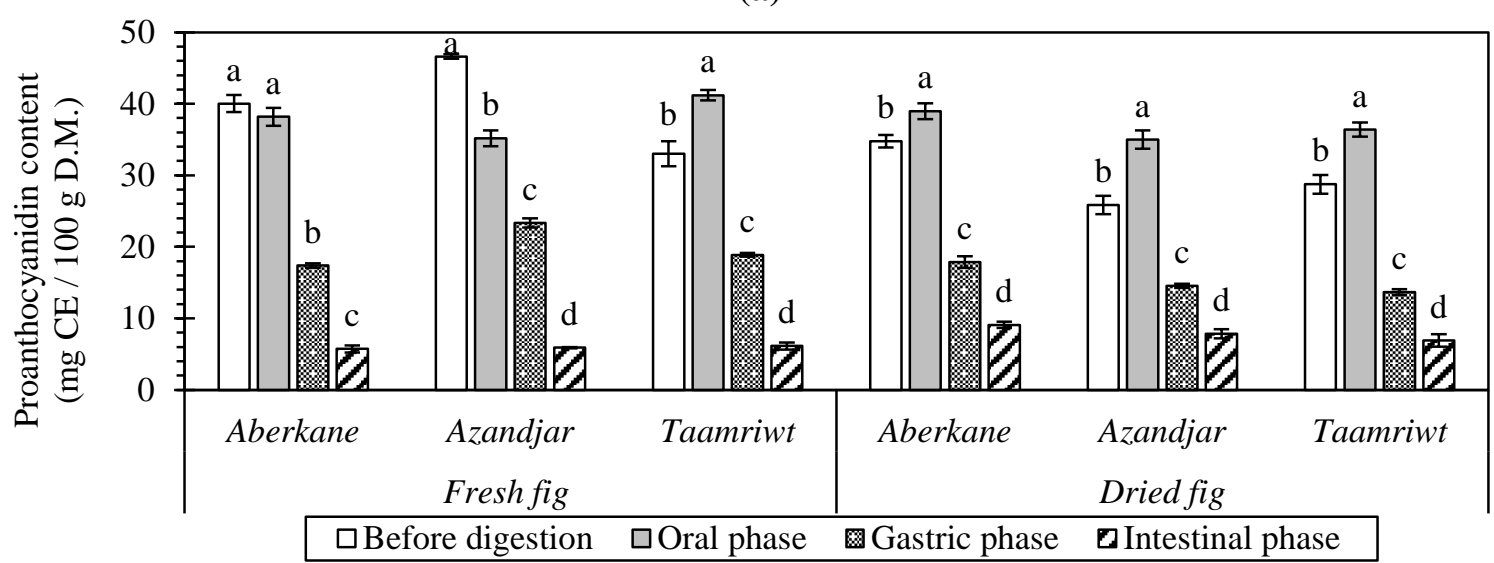

(b)

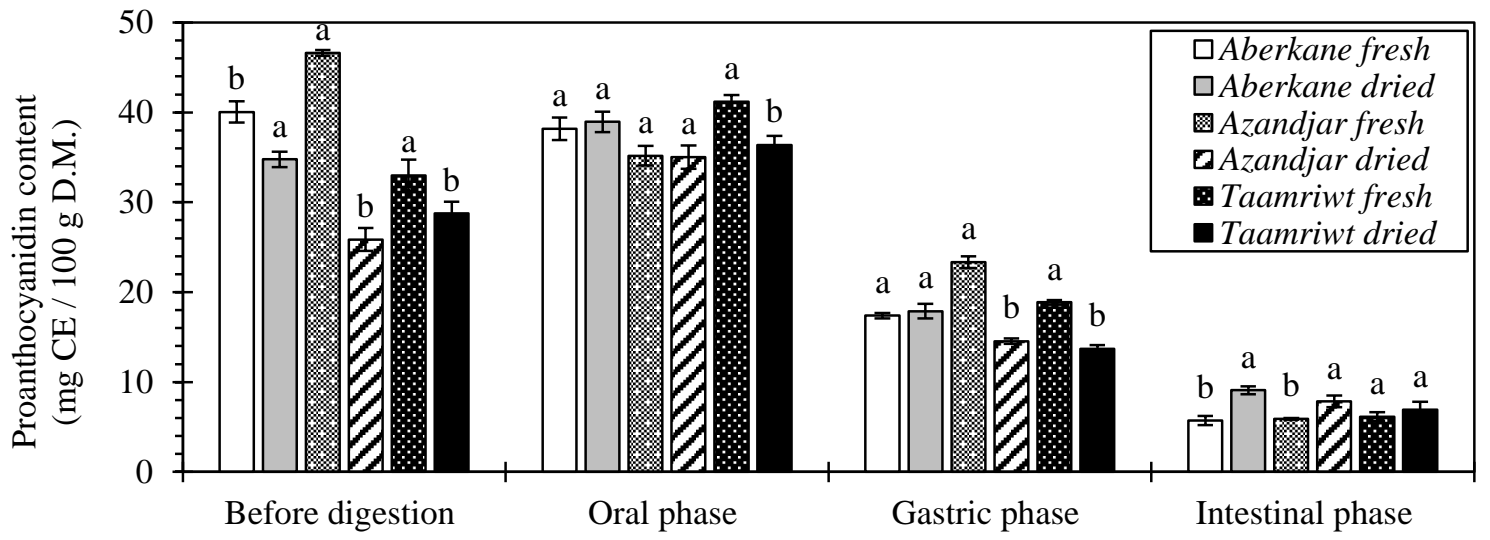

(c)

Figure 3. Varietal (a), in vitro gastrointestinal digestion (b), and sun-drying (c) effects on total proanthocyanidin content of fresh and dried figs during the in vitro gastrointestinal digestion phases (BD: before digestion, OP: oral phase, GP: gastric phase, IP: intestinal phase)Antioxidant activities

\section{Ferric reducing power}

The results of FRP are shown in Table 1. Before digestion, Aberkane and Taamriwt fresh varieties showed poor FRP with values of 513.93 and 491.26 mg AAE/100 g DM, respectively. While Azandjar fresh variety showed a higher FRP with value of $890.66 \mathrm{mg}$ AAE/100 g DM. However, the dried figs showed a higher FRP with values of 905.94 and
$711.91 \mathrm{mg}$ AAE/100 g DM for Aberkane and Azandjar varieties, respectively. Likewise, lowest FRP was recorded for Taamriwt variety $(493.84 \mathrm{mg}$ AAE/100 g DM). In, addition, a significant difference $(p<0.05)$ was revealed for the FRP after each IVGID phases for both fresh and dried fig varieties. 
After the oral phase, a significant decrease of FRP was observed with Azandjar and Taamriwt varieties extracts with rates of 61.56 and $71.35 \%$, respectively. The highest FRP was obtained with Aberkane variety followed by Azandjar and, Taamriwt varieties. These decreases were 73.44 , 73.24 and $41.53 \%$ for the Azandjar, Taamriwt and Aberkane varieties, respectively. After the intestinal phase, the FRP of the three varieties was significantly different $(p<0.05)$, and the results showed that Taamriwt variety has lost $81.72 \%$ of their FRP. Likewise, Azandjar and Aberkane varieties lost $77.96 \%$ and $69.04 \%$ of their FRP, respectively.

For the dried varieties, a significant decrease was observed between the FRP of three varieties studied. After the oral phase, the decrease rates of FRP was 56.16, 41.60 and $25.13 \%$ for the Aberkane, Azandjar and Taamriwt varieties, respectively. After the gastric phase, it appears that Aberkane variety has lost most of its FRP (70.94\%) and Taamriwt variety lost $60.79 \%$ of its FRP. Likewise, the Azandjar variety preserved more of its FRP with a decrease of $50.84 \%$. After the intestinal phase, the results show that Taamriwt dried variety has a higher FRP than the fresh state, while, the two darkcolored varieties lossed more noticeable of their FRP.

\section{Free radical scavenging activity}

The evaluation of FRSA of the three varieties of fresh and dried figs showed that this activity decreased after IVGID (Table 1). After the oral phase, FRSA of Aberkane, Azandjar and Taamriwt dried varieties decrease with rates of 47.98, 46.67 and $34.14 \%$ respectively. Likewise, after the gastric phase, a significant decrease $(p<0.05)$ was observed for the FRSA of Aberkane variety, which was $44.71 \%$. While, the Azandjar and Taamriwt varieties recorded insignificant decreases $(p>0.05)$, which were 47.10 and $34.16 \%$, respectively. After the final digestion phase, the decrease in FRSA was not marked for all varieties but remains significant $(p<0.05)$ compared to the previous phases. Furthermore, the decrease rates from the oral to the intestinal phases were in the range of 51.11, 53.63 and $38.6 \%$ for Aberkane, Azandjar and Taamriwt varieties, respectively.

For the varietal effect on the FRSA of fresh figs after each phase of $I V G I D$, the results revealed a significant difference $(p<0.05)$ between the three varieties. Before digestion, Azandjar variety showed a highest FRSA with value of $403.86 \mathrm{mg}$ AAE / $100 \mathrm{~g}$ DM followed by Aberkane variety (393.36 mg AAE / $100 \mathrm{~g} \mathrm{DM}$ ) and Taamriwt variety (321.47 mg AAE / $100 \mathrm{~g} \mathrm{DM}$ ). After oral phase, this activity recorded a significant decrease $(p<0.05)$ and Aberkane variety had the lowest value. Furthermore, the Aberkane variety showed a highest FRSA with value of $217.45 \mathrm{mg}$ AAE/100 g DM. Likewise, after the intestinal phase, Taamriwt variety showed a highest FRSA compared to those of dark color varieties despite their highest FRSA recorded before digestion.

For the dried figs, Aberkane variety showed a highest FRSA with value of $428.62 \mathrm{mg}$ AAE/100 g DM followed by Azandjar and Taamriwt varieties. After the oral phase, Azandjar variety present a highest activity than Aberkane and Taamriwt varieties. However, after the intestinal phase, Azandjar variety showed a highest FRSA followed by Taamriwt and Aberkane varieties.

\section{Phosphomolybdate activity}

The results of phosphomolybdate activity (PhM) before and during the IVGID of the three varieties of fresh and dried figs are presented in Table 1 . Before digestion, a strong PhM was recorded for the fresh figs of three varieties with values of 917.48, 872.54, and $807.70 \mathrm{mg}$ GAE/100 g DM for Azandjar, Taamriwt, and Aberkane varieties, respectively. However, a weak $\mathrm{PhM}$ was recorded for the dried figs of three varieties. Before digestion, the statistical analysis showed a significant difference $(p<0.05)$ between fresh figs and between dried figs of three varieties.

After the oral phase, a high decrease in $\mathrm{PhM}$ was observed for Aberkane fresh variety with rate of $83.06 \%$. Likewise, a fewer losses of $\mathrm{PhM}$ are recorded for Azandjar variety and they are estimated at $41.35 \%$. After the intestinal phase, the decreases in $\mathrm{PhM}$ activity was more intense with values of 98.13, 97.05, and $97.35 \%$ for the Aberkane, Azandjar, and Taamriwt varieties, respectively.

For dried figs, a significant decrease of $\mathrm{PhM}$ activity can be noted with both dark-colored varieties, which are estimated at 33.12 and $52.46 \%$ for the Aberkane and Azandjar varieties, respectively. In addition, the $\mathrm{PhM}$ activity of Taamriwt variety were not strong losses and most of this activity was preserved. The most affected during this digestion phase was the $\mathrm{PhM}$ activity of Aberkane variety, which was decreased at $94.42 \%$ followed by Azandjar and Taamriwt varieties with values of 90.36 and $89.31 \%$, respectively. After the intestinal phase, the results showed significant decreases of $\mathrm{PhM}(p<$ 0.05 ) for three varieties studied. In addition, the dried varieties display comparable $\mathrm{PhM}$ activity and were decreased from $96.65,94.52$, and $92.49 \%$ for Aberkane, Azandjar, and Taamriwt varieties, respectively. 


\section{Relationship between phenolic compounds and their antioxidant activities}

The variability of different varieties in the fresh and dry state was analyzed by PCA which explain $61.16 \%$ of the variability between the fresh and dry varieties (Figure 4). The circle of correlations is represented in Figure 4a. This plan consists of the first two factors; F1 and F2, which explain 33.97 and $27.20 \%$ of the variability, respectively. The factor F1 was positively correlated with TPC, TFC, FRP and FRSA. While, factor F2 was positively correlated with TFC, FRP and PhM.

The correlation circle allows the visualization of the correlations between variables that characterize the different varieties of fresh and dried figs and the correlations are given in Table 2. In the oral phase, a significant positive correlation can be noted between FRP and TFC $(r=0.669)$. However, FRP was negatively correlated with TPrC $(r=-0.657)$. After the gastric phase, a positive and high significant correlation was observed between the FRP and TPC $(r=0.758)$. In addition, a positive correlation was revealed between FRSA and TFC ( $\mathrm{r}$ $=0.626)$ in the oral phase and with $\operatorname{TPrC}(\mathrm{r}=0.651)$ in the gastric phase. The results showed that before digestion, $\mathrm{PhM}$ was positively correlated with TFC $(\mathrm{r}=0.635)$ and was highly significant with $\mathrm{TPrC}(\mathrm{r}$ $=0.802)$. Likewise, high significant and positive correlations was noted after the gastric phase between PhM and TFC $(r=0.923)$ and between
$\mathrm{PhM}$ and $\mathrm{TPrC}(\mathrm{r}=0.823)$. Furthermore, $\mathrm{PhM}$ was positively correlated with $\operatorname{TPrC}(r=0.705)$ at the end of digestion.

In order to analyze the variability of the varieties in their fresh and dry states as a function of the contents of phenolic compounds and their antioxidant activities, the biplot was obtained by superimposing the plan of the samples with that of the variables (Figure $4 b$ ). The six samples were grouped into three different groups as shown in Figure $4 c$ which represents the dendrogram of the hierarchical relationship between fresh and dried varieties. The first group represents Taamriwt variety in both fresh and dried states. This group was not associated with any characteristic, and this might be due to the low contents of phenolic compounds and poor antioxidant activities. Likewise, the second group brined together Aberkane and Azandjar dried varieties, which are associated with high levels of TFC and TPrC at the end of IVGID. This group was also associated with antioxidant activities, such as FRSA before digestion and after the oral phase and FRP after the oral and gastric phases. The third group represents fresh figs of Aberkane and Azandjar varieties, which are associated with very high levels of TPC after the oral phase, TFC before digestion, TPrC before digestion and antioxidant activities such as FRSA after the gastric phase and FRP before and after IVGID.
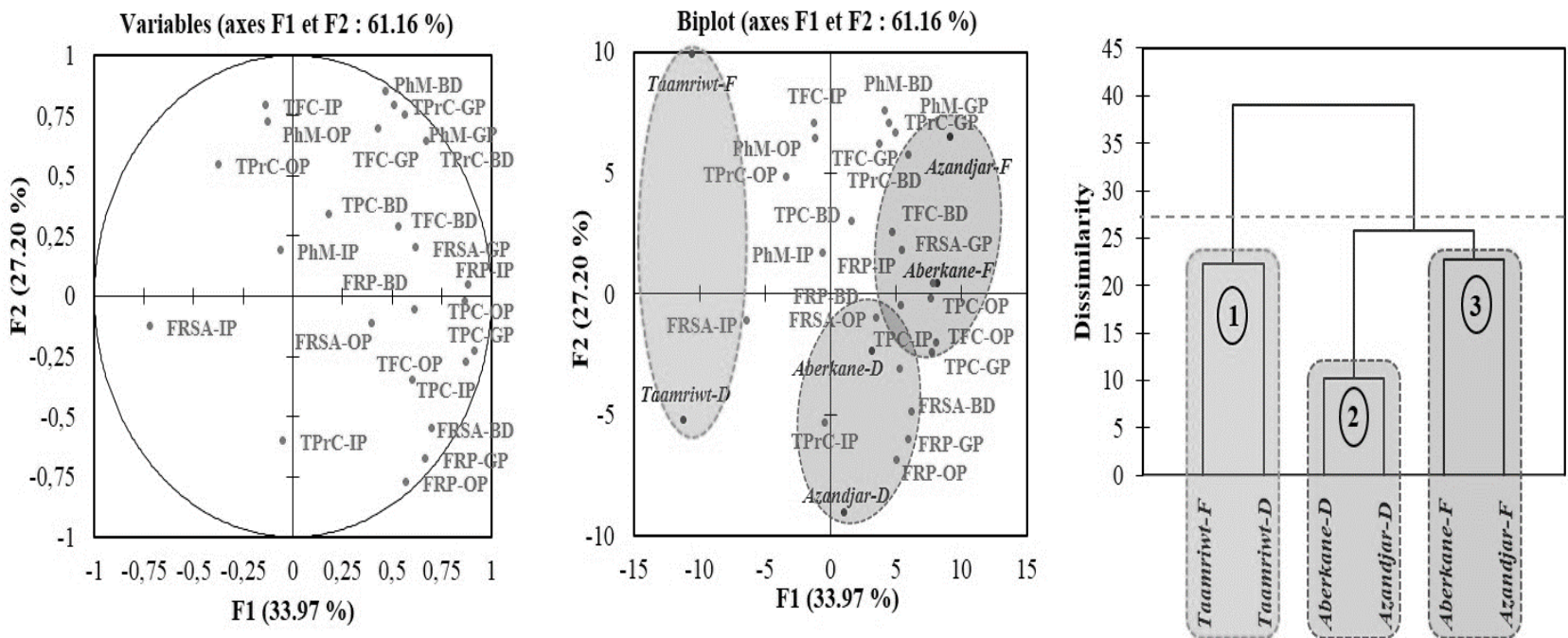

Figure 4. Principal components analysis for variability of fresh and dried figs varieties. Correlation circle between the parameters characterizing the varieties of fresh and dried figs and their compositions in phenolic compounds and antioxidant activities (a). Biplot of variability of fresh and dried fig varieties (b). Dendrogram of the hierarchical relationship between fresh and dried varieties (c). F: fresh, D: dried, TPC: total phenolics content, TFC: total flavonoid content, TPrC: total prothocyanidin content, FRP: ferric reducing power, FRSA: Free radical scavenging activity, PhM: phosphomolybdate activity, BD: before digestion, OP: oral phase, GP: gastric phase, IP: intestinal phase 


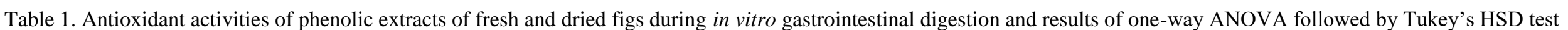
for multiple comparison

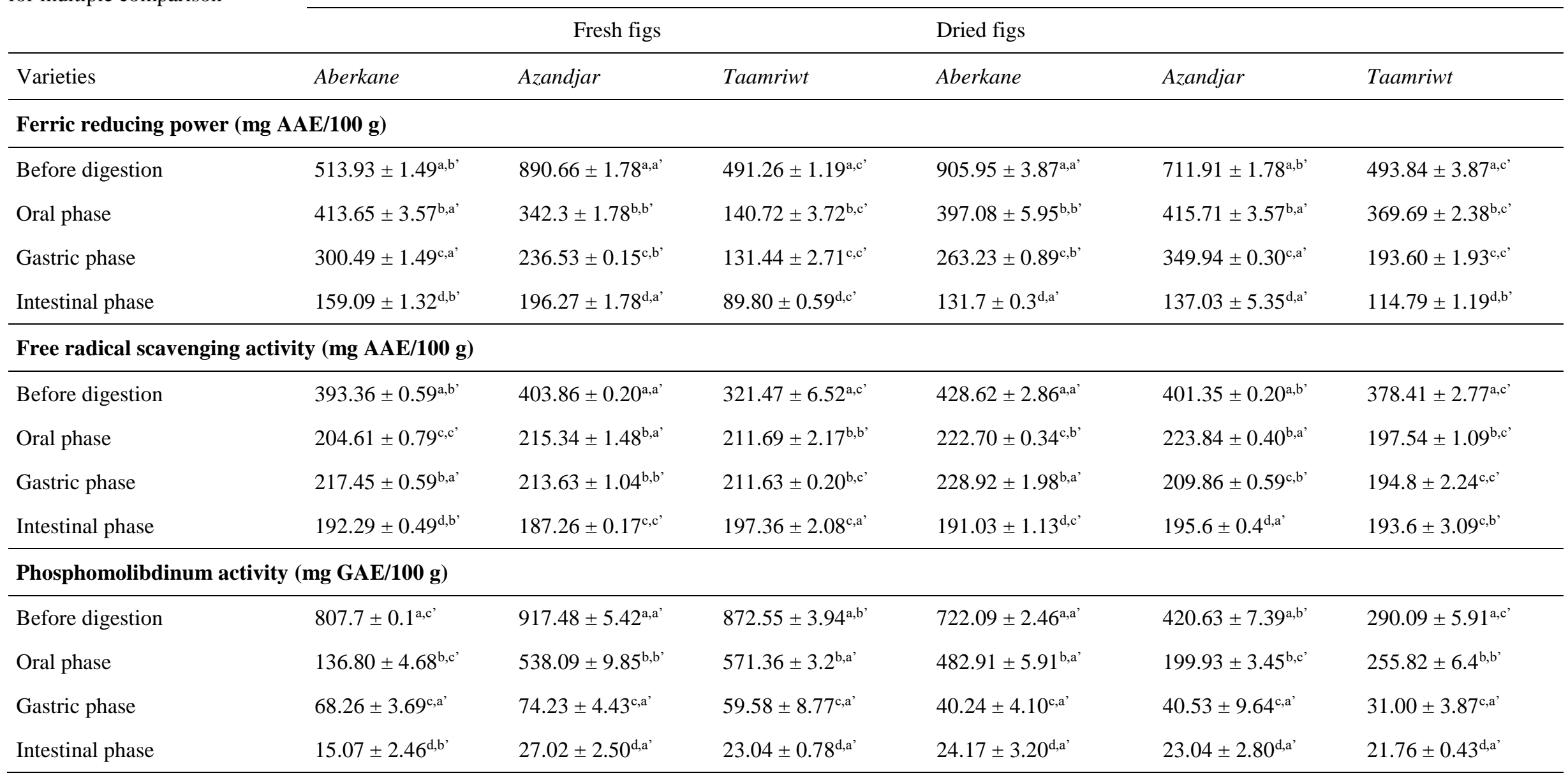


Table 2. Correlation matrix between the phenolic compounds contents and their antioxidant activities

\begin{tabular}{|c|c|c|c|c|c|c|c|c|c|c|c|c|}
\hline Variables & FRP-BD & FRP-OP & FRP-GP & FRP-IP & FRSA-BD & FRSA-OP & FRSA-GP & FRSA-IP & PhM-BD & PhM-OP & PhM-GP & PhM-IP \\
\hline TPC-BD & -0440 & & & & -0.353 & & & & 0.499 & & & \\
\hline TPC-OP & & 0.439 & & & & 0.356 & & & & -0.351 & & \\
\hline TPC-GP & & & $0.758 * *$ & & & & 0.374 & & & & 0.420 & \\
\hline TPC-IP & & & & 0.197 & & & & -0.016 & & & & -0.286 \\
\hline TFC-BD & -0.033 & & & & 0.099 & & & & $0.635^{*}$ & & & \\
\hline TFC-OP & & $0.669 *$ & & & & $0.626^{*}$ & & & & -0.311 & & \\
\hline TFC-GP & & & -0.184 & & & & 0.057 & & & & $0.923 * * *$ & \\
\hline TFC-IP & & & & -0.079 & & & & -0.082 & & & & $0.705^{* *}$ \\
\hline TPrC-BD & 0.375 & & & & 0.198 & & & & $0.802 * * *$ & & & \\
\hline TPrC-OP & & $-0.657^{*}$ & & & & -0.097 & & & & 0398 & & \\
\hline TPrC-GP & & & -0.239 & & & & $0.651 *$ & & & & $0823 * * *$ & \\
\hline TPrC-IP & & & & -0.253 & & & & 0.061 & & & & 0.309 \\
\hline
\end{tabular}

*significant correlation, $* *$ very significant correlation, $* * *$ high significant correlation.

BD: before digestion, OP: oral phase, GP: gastric phase, IP: intestinal phase, TPC: total polyphenols contents, TFC: total flavonoid contents, TPrC: total proanthocyanidin contents, FRP: ferric reducing power, FRSA: free radical scavenging activity, PhM: phosphomolybdate activ 


\section{DISCUSSION}

The varieties with dark skin showed high levels of phenolic compounds such as TPC, TFC, and TPrC compared to the light-skinned variety. These dark varieties showed more antioxidant activity than the light one. The results of this study was an agreement with those reported previously by (Bachir Bey and Louaileche, 2015). According to the results reported in the literature (Solomon et al., 2006), the color difference between varieties may be due to the expression of genes that control the synthesis of anthocyanins; high expression is associated with varieties with dark skin.

The sun-drying of figs can play a negative influence on phenolic compound contents (TPC, TFC, and TPrC) and on their antioxidant activities (FRP, FRSA, and PhM). This decrease may be the result of the enzymatic degradation of phenolic compounds, especially flavonoids and anthocyanins, by polyphenol oxidases (PPO) and peroxidases which are not inactivated by the insufficiently high temperatures of sun-drying (Lim and Murtijaya, 2007; Li et al., 2018). Sun-drying temperatures varied between 30 and $40{ }^{\circ} \mathrm{C}$, which are activation temperatures of these enzymes (Mizobutsi et al., 2010). Phenolic compounds play a protective role in the plant. During sun drying, flavonoids act as filters against UV rays by protecting some cell structures such as chloroplasts, which leads to a reduction in these contents (Treutter, 2010; Bachir Bey, 2017). The concentration of sugars, the interaction of polyphenols with organic acids and proteins, changes in the chemical structure, the efficiency of extraction can also cause losses in these compounds (De Ancos et al., 2000; Mueller-Harvey, 2001; Gümüşay et al., 2015).

The decrease in antioxidant activity after sun-drying can be explained by the decrease in the phenolic compounds contents, especially flavonoids which play a pivotal role in the antioxidant activity, and the degradation of other antioxidants such as vitamins, carotenoids and amino acids under sundrying effect (Kamiloglu et al., 2016; Matłok et al., 2020).

Whatever the nature of the fresh or dried figs, the decrease in the phenolic compounds contents during the in vitro gastrointestinal digestion can be explained by the instability of these compounds under simulated digestion conditions. During digestion, phenolic compounds undergo changes due to mechanical action, enzymatic activity and the effect of $\mathrm{pH}$. The in vitro gastrointestinal conditions lead to the hydrolysis of some phenolic compounds and interactions with the released products after hydrolysis. Other components of the food matrix released after gastric digestion can cause the change in molecular weight, in solubility, and in structure, which results in poor phenolic compounds extractability from the food matrix (Chen et al., 2016; Seraglio et al., 2018).

The increase in the phenolic compounds content after the oral and gastric phase is noted especially for the clear variety. These results agree with those reported in literature (Bouayed et al., 2011), which be explained by the extraction time which was 2 hours and the effect of digestive enzymes on the food matrix by facilitating the release of phenolic compounds linked to the matrix. Furthermore, the decrease in TPrC during the digestion phases can be explained by the interaction between these compounds and proteins (used enzymes and proteins from figs). One of the characteristic properties of tannins is their ability to precipitate proteins from aqueous solutions (Bennick, 2002). Indeed, an in vivo study on rats having ingested a diet enriched with tannins shows a decrease in the enzymatic activity of two enzymes of the digestive system, which are trypsin and $\alpha$-amylase (Dupas et al., 2005). However, the interactions between proteins and polyphenols lead to a decrease in the bioavailability of phenolic acids (Roowi et al., 2009). On the other hand, a low TPrC obtained before digestion compared to the oral phase can be explained by the interaction between fruits tannins and polysaccharides, which causes a modification of their structure (Dupas et al., 2005). The extraction time during the oral phase was very short compared to before digestion, this may cause an insufficient contact time between the tannins and the polysaccharides.

The decrease in FRSA can be explained by the incomplete release or degradation of antioxidants. Indeed, the alteration of the structure of antioxidants during digestion can affect their reactivity with the formation of free radicals (Morelló et al., 2004). In addition to the dependence of the phenolic compounds activity on ambient conditions, such as the $\mathrm{pH}$ and the interaction of these phenolic compounds with other dietary constituents released during digestion (iron, minerals, dietary fibers or proteins), solubility and bioavailability of polyphenols may be affected by these conditions.

Similarly, these factors would have an impact on their antioxidant potential (Bouayed et al., 2011). Due to the $\mathrm{pH}$ conditions of the antioxidant activity tests performed in this study, one would assume that the FRP test leading to a $\mathrm{pH}$ of 6.6 might be more suitable for assessing the antioxidant activity of intestinal digestion than gastric digestion. 
Finally, the measurement of antioxidant activities, particularly in the case of multifunctional or complex multi-phase systems, can not be satisfactorily assessed by a single method. Therefore, several tests must be performed as done in this study.

The correlation between the antioxidant activity and TFC was higher than those found with TPC and TPrC. Indeed, the antioxidant capacity was strongly linked to TFC and modestly linked to TPC and TPrC. This means that there is a potential synergistic effect between the antioxidants. However, a negative correlations noted with antioxidant activity and some phenolic compounds could be explained by the fact that antioxidant activity is not always related to the phenolic compounds content but also to their qualities, which play a critical role for this activity. In some cases,

\section{CONCLUSION}

The present study showed that the total phenolic compounds (TPC, TFC, and TPrC) and their antioxidant capacities (FRP, FRSA, and PhM) of the three fresh and dried figs varieties (Aberkane, Azandjar, and Taamriwt) decreased significantly after the IVGID. Before digestion, high phenolic compound contents and high antioxidant activities were observed. However, after digestion, phenolic and antioxidant activities decreased significantly from the oral phase to the intestinal phase. despite the high phenolic compound contents, their biological activities remain low (Morelló et al., 2004).

From the obtained results, it can be concluded that there is a positive correlation between the phenolic compound contents and the antioxidant activities. Indeed, this coordination confirmed that TPC, TFC and $\mathrm{TPrC}$ are responsible of the antioxidant activity tested. Therefore, the antioxidant activity of the phenolic compounds can be linked to their redox properties, which allow them to act as reducing agents or donating hydrogen atom giving it the ability to chelate metals, inhibit lipoxygenase and eliminate free radicals (Mishra et al., 2012).

However, the lack of correlation could be due to the presence of other antioxidants in the extracts, which are at the origin of the activity detected.

A positive correlation was observed between the phenolic compounds and the tested antioxidant activities. Therefore, IVGID has an effect on phenolic compounds and their antioxidant potential, where $\mathrm{pH}$ and enzymes have a negative influence on the amount of these compounds and their activities. No significant effect of the variety and sun-drying was reveled on the content of phenolic compounds and their antioxidant activity during in vitro gastrointestinal digestion. Likewise, the fresh or dry variety kept a high content before and after the digestion.

\section{Acknowledgements}

The authors would like to greatly acknowledge Miss Lamia Elmechta (lecturer of English, INATAA, UFMC 1) who provided language help and Mr. Abdelhek Ounas (member of the cooperative of fig growers of Beni Maouche, Bejaia) for providing the plant material.

\section{REFERENCES}

1. Bachir Bey, M. \& Louaileche, H. (2015). A comparative study of phytochemical profile and in vitro antioxidant activities of dark and light dried fig (Ficus carica L.) varieties. The Journal of Phytopharmacology, 4(1), 41-48.

2. Bachir Bey, M., Richard, G., Meziant, L., Fauconnier, M.L. \& Louaileche, H. (2017). Effects of sundrying on physicochemical characteristics, phenolic composition and in vitro antioxidant activity of dark fig varieties. Journal of Food Processing and Preservation, 41(5), 1-8. https://doi.org/10.1111/jfpp.13164

3. Bennick, A. (2002). Interaction of plant polyphenols with salivary proteins. Critical Reviews in Oral Biology \& Medicine, 13(2), 184-196. https://doi.org/10.1177/154411130201300208

4. Bouayed, J., Hoffmann, L. \& Bohn, T. (2011). Total phenolics, flavonoids, anthocyanins and antioxidant activity following simulated gastro-intestinal digestion and dialysis of apple varieties: Bioaccessibility and potential uptake. Food Chemistry, 128(1), 14-21. https://doi.org/10.1016/j.foodchem.2011.02.052 
5. Chaalal, M., Ydjedd, S., Harkat, A., Namoune, H. \& Kati, D. (2018). Effect of in vitro gastrointestinal digestion on antioxidant potential of three prickly pear variety extracts. Acta Alimentaria, 47(3), 333-339. https://doi.org/10.1556/066.2018.47.3.9

6. Chawla, A., Kaur, R. \& Sharma, A.K. (2012). Ficus carica Linn.: A review on its pharmacognostic, phytochemical and pharmacological aspects. International Journal of Pharmaceutical and Phytopharmacological Research, 1(4), 215-232.

7. Chen, G-L., Chen, S-G., Chen, F., Xie, Y-Q., Han, M-D., Luo, C-X., Zhao, Y-Y. \& Gao, Y-Q. (2016). Nutraceutical potential and antioxidant benefits of selected fruit seeds subjected to an in vitro digestion. Journal of Functional Foods, 20, 317-331. https://doi.org/10.1016/j.jff.2015.11.003

8. De Ancos, B., Ibanez, E., Reglero, G. \& Cano, M.P. (2000). Frozen storage effects on anthocyanins and volatile compounds of raspberry fruit. Journal of Agricultural and Food Chemistry, 48(3), 873-879. https://doi.org/10.1021/jf990747c

9. Debib, A., Tir-Touil, A., Mothana, R.A., Meddah, B. \& Sonnet, P. (2014). Phenolic Content, Antioxidant and Antimicrobial Activities of Two Fruit Varieties of Algerian Ficus carica L. Journal of Food Biochemistry, 38(2), 207-215. https://doi.org/10.1111/jfbc.12039

10. Dewanto, V., Wu, X., Adom, K.K. \& Liu, R.H. (2002). Thermal Processing Enhances the Nutritional Value of Tomatoes by Increasing Total Antioxidant Activity. Journal of Agricultural and Food Chemistry, 50(10), 3010-3014. https://doi.org/10.1021/jf0115589

11. Dupas, C., Marsset-Baglier, A.C., Ordonaud, C.S., Ducept, F.M.G. \& Maillard, M-N. (2005). Coffee Antioxidant Properties: Effects of Milk Addition and Processing Conditions. Journal of Food Science, 71(3), S253-S258. https://doi.org/10.1111/j.1365-2621.2006.tb15650.x

12. Food and Agricultural Organization of the United Nations, 2014. FAOSTAT database. http://faostat.fao.org (accessed 14 February 2018).

13. Granese, T., Cardinale, F., Cozzolino, A., Pepe, S., Ombra, M.N., Nazzaro, F., Coppola, R. \& Fratianni, F. (2014). Variation of Polyphenols, Anthocyanins and Antioxidant Power in the Strawberry Grape (Vitis labrusca) after Simulated Gastro-Intestinal Transit and Evaluation of in vitro Antimicrobial Activity. Food and Nutrition Sciences, 05(1), 60-65. DOI:10.4236/fns.2014.51008

14. Gullon, B., Pintado, M.E., Fernández-López, J., Pérez-Álvarez, J.A. \& Viuda-Martos, M. (2015). In vitro gastrointestinal digestion of pomegranate peel (Punica granatum) flour obtained from co-products: Changes in the antioxidant potential and bioactive compounds stability. Journal of Functional Foods, 19, 617-628. https://doi.org/10.1016/j.jff.2015.09.056

15. Gümüşay, Ö.A., Borazan, A.A., Ercal, N. \& Demirkol, O. (2015). Drying effects on the antioxidant properties of tomatoes and ginger. Food Chemistry, 173, 156-162. https://doi.org/10.1016/j.foodchem.2014.09.162

16. Jolayemi, O.S., Olanrewaju, O.J. \& Ogunwale, O. (2020). Exploring in vitro antioxidant activity and physicochemical properties of selected under-exploited tropical fruits. Acta Universitatis Cinbinesis, Series E: Food Technology, 24(2), 165-174. https://doi.org/10.2478/aucft-2020-0015

17. Kamiloglu, S. \& Capanoglu, E. (2013). Investigating the in vitro bioaccessibility of polyphenols in fresh and sun-dried figs (Ficus carica L.). International Journal of Food Science Technology, 48(12), 26212629. https://doi.org/10.1111/ijfs. 12258

18. Kamiloglu, S., Pasli, A.A., Ozcelik, B., Van Camp, J. \& Capanoglu, E. (2015). Colour retention, anthocyanin stability and antioxidant capacity in black carrot (Daucus carota) jams and marmalades: Effect of processing, storage conditions and in vitro gastrointestinal digestion. Journal of Functional Foods, 13, 1-10. https://doi.org/10.1016/j.jff.2014.12.021

19. Kamiloglu, S., Toydemir, G., Boyacioglu, D., Beekwilder, J., Hall, R.D. \& Capanoglu, E. (2016). A Review on the Effect of Drying on Antioxidant Potential of Fruits and Vegetables. Critical Reviews in Food Science and Nutrition, 56, S110-S129. https://doi.org/10.1080/10408398.2015.1045969

20. Kumaran, A. \& Joel karunakaran, R. (2006). Antioxidant and free radical scavenging activity of an aqueous extract of Coleus aromaticus. Food Chemistry, 97(1), 109-114. https://doi.org/10.1016/j.foodchem.2005.03.032

21. Li, R., Shang, H., Wu, H., Wang, M., Duan, M. \& Yang, J. (2018). Thermal inactivation kinetics and effects of drying methods on the phenolic profile and antioxidant activities of chicory (Cichorium intybus L.) leaves. Scientific Reports, 8(1), 1-9. https://doi.org/10.1038/s41598-018-27874-4 
22. Lim, Y.Y. \& Murtijaya, J. (2007). Antioxidant properties of Phyllanthus amarus extracts as affected by different drying methods. LWT food science and technology, 40(9), 1664-1669. https://doi.org/10.1016/j.lwt.2006.12.013

23. Matłok, N., Gorzelany, J., Piechowiak, T. \& Balawejder, M. (2020). Influence of drying temperature on the content of bioactive compounds in scots pine (Pinus sylvestris L.) Shoots as well as yield and composition of essential oils. Acta Universitatis Cinbinesis, Series E: Food Technology, 24(1), 15-24. https://doi.org/10.2478/aucft-2020-0002

24. Minekus, M., Alminger, M., Alvito, P., Ballance, S., Bohn, T., Bourlieu, C., Carriere, F., Boutrou, R., Corredig, M. \& Dupont, D. (2014). A standardised static in vitro digestion method suitable for food-an international consensus. Food \& function, 5(6), 1113-1124. DOI: 10.1039/C3FO60702J

25. Mishra, K., Ojha, H. \& Chaudhury, NK. (2012). Estimation of antiradical properties of antioxidants using DPPH assay: A critical review and results. Food Chemistry, 130(4), 1036-1043. https://doi.org/10.1016/j.foodchem.2011.07.127

26. Mizobutsi, G.P., Finger, F.L., Ribeiro, R.A., Puschmann, R., Neves, L.L.D.M. \& Mota, W.F.D. (2010). Effect of $\mathrm{pH}$ and temperature on peroxidase and polyphenoloxidase activities of litchi pericarp. Scientia Agricola, 67(2), 213-217. https://doi.org/10.1590/S0103-90162010000200013

27. Morelló, J-R., Motilva, M-J., Tovar, M-J. \& Romero, M-P. (2004). Changes in commercial virgin olive oil (cv Arbequina) during storage, with special emphasis on the phenolic fraction. Food Chemistry, 85(3), 357-364. https://doi.org/10.1016/j.foodchem.2003.07.012

28. Mueller-Harvey, I. (2001). Analysis of hydrolysable tannins. Animal Feed Science and Technology, 91(12), 3-20. https://doi.org/10.1016/S0377-8401(01)00227-9

29. Oyaizu, M. (1986). Studies on products of browning reaction. The Japanese Journal of Nutrition and Dietetics, 44(6), 307-315.

30. Prieto, P., Pineda, M. \& Aguilar, M., (1999). Spectrophotometric quantitation of antioxidant capacity through the formation of a phosphomolybdenum complex: specific application to the determination of vitamin E1. Analytical biochemistry, 269(2), 337-341. https://doi.org/10.1006/abio.1999.4019

31. Roowi, S., Mullen, W., Edwards, C.A. \& Crozier, A. (2009). Yoghurt impacts on the excretion of phenolic acids derived from colonic breakdown of orange juice flavanones in humans. Molecular Nutrition \& Food Research, 53, S68-S75. https://doi.org/10.1002/mnfr.200800287

32. Saura-Calixto, F., Serrano, J. \& Goñi, I. (2007). Intake and bioaccessibility of total polyphenols in a whole diet. Food Chemistry, 101(2), 492-501. https://doi.org/10.1016/j.foodchem.2006.02.006

33. Seraglio, S.K.T., Gonzaga, L.V., Schulz, M., Vitali, L., Micke, G.A., Costa, A.C.O., Fett, R. \& Borges, G.D.C. (2018). Effects of gastrointestinal digestion models in vitro on phenolic compounds and antioxidant activity of juçara (Euterpe edulis). International Journal of Food Science Technology, 53(8), 1824-1831. https://doi.org/10.1111/ijfs.13816

34. Škerget, M., Kotnik, P., Hadolin, M., Hraš, A.R., Simonič, M. \& Knez, Ž. (2005). Phenols, proanthocyanidins, flavones and flavonols in some plant materials and their antioxidant activities. Food Chemistry, 89(2), 191-198. https://doi.org/10.1016/j.foodchem.2004.02.025

35. Solomon, A., Golubowicz, S., Yablowicz, Z., Grossman, S., Bergman, M., Gottlieb, H.E., Altman, A., Kerem, Z. \& Flaishman, M.A. (2006). Antioxidant Activities and Anthocyanin Content of Fresh Fruits of Common Fig (Ficus carica L.). Journal of Agricultural and Food Chemistry, 54(20), 7717-7723. https://doi.org/10.1021/jf060497h

36. Spanos, G.A. \& Wrolstad, R.E. (1990). Influence of processing and storage on the phenolic composition of Thompson Seedless grape juice. Journal of Agricultural and Food Chemistry, 38(7), 1565-1571. https://doi.org/10.1021/jf00097a030

37. Treutter, D. (2006). Significance of flavonoids in plant resistance: a review. Environmental Chemistry Letters, 4(3), 147-157. https://doi.org/10.1007/s10311-006-0068-8

38. Ydjedd, S. , Bouriche, S., López-Nicolás, R., Sánchez-Moya, T., Frontela-Saseta, C., Ros-Berruezo, G., Rezgui, F., Louaileche, H. \& Kati, D.E. (2017). Effect of in Vitro Gastrointestinal Digestion on Encapsulated and Nonencapsulated Phenolic Compounds of Carob (Ceratonia siliqua L.) Pulp Extracts and Their Antioxidant Capacity. Journal of Agricultural and Food Chemistry, 65(4), 827-835. https://doi.org/10.1021/acs.jafc.6b05103

39. Zoubiri, L. , Bakir, S., Barkat, M., Carrillo, C. \& Capanoglu, E. (2019). Changes in the phenolic profile, antioxidant capacity and in vitro bioaccessibility of two Algerian grape varieties, Cardinal and Dabouki 
(Sabel), during the production of traditional sun-dried raisins and homemade jam. Journal of Berry Research, 9(4), 709-724. DOI: 10.3233/JBR-190432 